\title{
CINÉTICA DE SECAGEM E AVALIAÇÃO FÍSICO-QUÍMICA DA GOIABA DESIDRATADA EM UM PROTÓTIPO DE SECADOR SOLAR
}

\author{
COELHO, Bruno Emanuel Souza ${ }^{1}$ \\ NASCIMENTO, Mayane Mendes do ${ }^{2}$ \\ SOUSA, Karla dos Santos Melo de ${ }^{3}$ \\ COELHO, Carmem Lúcia ${ }^{4}$ \\ MACHADO, Neiton Silva ${ }^{5}$
}

Recebido em: 2020.03.04

Aprovado em: 2020.07.23

ISSUE DOI: $10.3738 / 1982.2278 .3749$

\begin{abstract}
RESUMO: Por se tratar de um processo simples e de baixo custo, a secagem natura, utilizando energia solar e equipamentos de baixo custo torna-se uma alternativa viável e acessível aos pequenos produtores rurais. A goiaba é um fruto climatérico e altamente perecível. A descrição do processo de secagem é de extrema importância para a obtenção de produtos de boa qualidade. Este trabalho teve como objetivo desenvolver um protótipo de secador solar de baixo custo e de exposição direta para a desidratação de goiaba, além de avaliar a eficiência do processo, e a qualidade físico-química do produto final. O protótipo foi desenvolvido utilizando materiais alternativos e de baixo custo. A eficiência do processo foi avaliada através da cinética de secagem e do ganho de temperatura do secador. A matéria-prima e o produto final foram avaliados quanto aos parâmetros físico-químicos e cor. O processo de secagem possibilitou a secagem dos frutos de goiaba dentro de um período de 15 horas, com incremento médio de temperatura de $19,7^{\circ} \mathrm{C}$. O modelo de Handerson e Pabis foi o que melhor se ajustou para predição do processo. A secagem solar levou a uma redução significativa do $\mathrm{pH}$ e do teor de água. Em relação à acidez e teor de sólidos solúveis, observou-se um aumento significativo após a secagem. Com relação a vitamina C, verificou-se um aumento de cerca de $500 \%$ na concentração em relação ao teor na goiaba in natura.
\end{abstract}

Palavras-chave: Agricultura familiar. Alimento atrativo. Fruta seca. Psidium guajava. Vitamina C.

\section{DRYING KINETICS AND PHYSICAL AND CHEMICAL EVALUATION OF DEHYDRATED GUIA IN A SOLAR DRYER PROTOTYPE}

SUMMARY: Because it is a simple and low-cost process, natural drying, using solar energy and low-cost equipment, becomes a viable and accessible alternative for small rural producers. Guava is a climacteric and highly perishable fruit. The description of the drying process is extremely important to obtain good quality products. This work aimed to develop a low-cost, direct-exposure solar dryer prototype for guava dehydration, in addition to evaluating the efficiency of the process and the physical-chemical quality of the final product. The prototype was developed using alternative and lowcost materials. The efficiency of the process was evaluated through the drying kinetics and the temperature gain of the dryer. The raw material and the final product were evaluated for physical-chemical parameters and color. The drying process made it possible to dry the guava fruits within 15 hours, with an average temperature increase of $19.7^{\circ} \mathrm{C}$. The Handerson and Pabis model was the one that best fit to predict the process. Solar drying led to a significant reduction in $\mathrm{pH}$ and water content. Regarding acidity and soluble solids content, a significant increase was observed after drying. Regarding vitamin C, there was an increase of about 500\% in the concentration in relation to the content of fresh guava.

Keywords: Family farming. Attractive food. Dry fruit. Psidium guajava L. Vitamin C.

\footnotetext{
${ }^{1}$ Mestrando em Agronomia - Produção Vegetal, Universidade Federal do Vale do São Francisco - CCA, Petrolina, Pernambuco, Brasil. Orcid: http://orcid.org/0000-0002-4526-6369

${ }^{2}$ Graduanda em Engenharia Agronômica, Universidade Federal do Vale do São Francisco - CCA, Petrolina, Pernambuco, Brasil.

${ }^{3}$ Professora Adjunta, Universidade Federal do Vale do São Francisco - CCA, Petrolina, Pernambuco, Brasil.

${ }^{4}$ Graduanda em Tecnologia em Alimentos - Instituto Federal de Educação, Ciência e Tecnologia do Sertão Pernambucano - campus Petrolina.

${ }^{5}$ Professor Adjunto, Universidade Federal do Vale do São Francisco - CCA, Petrolina, Pernambuco, Brasil.
} 


\section{INTRODUÇÃO}

A goiabeira (Psidium guajava L.) é uma planta originária do Norte da América do Sul, pertence à família Myrtaceae, presente principalmente em regiões tropicais e subtropicais (SANTANA et al., 2016). No Brasil, aproximadamente 32\% da produção de goiaba é proveniente de regiões de clima semiárido (IBGE, 2016). Na região Nordeste, a região semiárida beneficiada pela bacia do rio São Francisco concentra importantes áreas produtivas de goiaba, pois possui além de disponibilidade hídrica, as condições de clima e solo favoráveis ao cultivo (RODRIGUES et al., 2015).

A goiaba é um fruto climatérico, altamente perecível, possuindo uma perda muito rápida da coloração verde da casca, amolecimento excessivo, elevada incidência de podridões, murchamento e perda de brilho (VISHWASRAO; ANANTHANARAYAN, 2016). Além disso, apresenta uma vida de prateleira máxima de oito dias, sendo um dos maiores problemas enfrentados para a sua comercialização in natura (GILL et al., 2016).

No Brasil, a goiaba é apreciada pelos consumidores por possuir sabor forte e quantidades consideráveis de vitamina $\mathrm{C}$, porém, a sua curta vida pós-colheita associada ao elevado conteúdo de água torna o fruto susceptível a danos causados no transporte e armazenamento, limitando o seu potencial de comercialização (SAHOO et al., 2015).

Com o intuito, de reduzir as atividades fisiológicas, microbiológicas, reações enzimáticas e não enzimáticas, a secagem é um mecanismo empregado para a conservação de frutas, baseando-se na redução do teor de água pelo uso do calor, resultando na diminuição do volume do fruto, com consequente redução dos custos com embalagem, armazenamento e transporte, visto que não necessita de refrigeração, e além de agregar valor ao produto, e consequentemente aumentando a estabilidade (VASCONCELOS et al., 2012).

$\mathrm{O}$ método tradicional de secagem geralmente utiliza fontes térmicas, que se baseiam no uso de lenha ou carvão como combustíveis sólidos para promover o aquecimento do ar, podendo acarretar em contaminação do produto a ser secado, além do elevado potencial poluente, encarecendo o produto final, e de fontes elétricas, que tem como maior desvantagem o consumo de níveis altos de energia e alto custo operacional (SATER et al., 2011).

Como alternativa, o desenvolvimento de equipamentos, que utilizam a radiação solar com eficiência e que demandam baixo custo na sua fabricação, adquiriram relevância hodiernamente, uma vez que apresenta-se uma solução para os pequenos produtores rurais que desempenham suas Nucleus, v.17, n.2, out.2020 
atividades laborais no contexto familiar e que não possuem poder aquisitivo suficiente para terem acesso a equipamentos de secagem mais sofisticados (PRAKASH; ANILKUMAR, 2013).

E o uso da energia solar na secagem de alimentos é uma alternativa altamente viável em todo o Brasil, pelas condições meteorológicas favoráveis, e principalmente no Nordeste, e em regiões de clima semiárido, destacando-se seu potencial econômico, e por utilizar um recurso limpo, gratuito e abundante (o sol), e por não necessitar de mão de obra especializada (SILVA et al., 2013).

A descrição do processo de secagem é de extrema importância para a obtenção de produtos de boa qualidade. É através da cinética de secagem que é possível estudar o comportamento da transferência de massa entre o produto e o agente de secagem, gerando informações do processo, possibilitando a determinação do mecanismo predominante na transferência de massa do material para o fluído (SILVA et al., 2013; MOREIRA et al., 2016).

O emprego da modelagem matemática é de empregado para estudar e representar o processo de secagem, pois as informações geradas são de grande valia no processo de desenvolvimento de equipamentos e predição de tempos de secagem (FARIA et al., 2012; SOUSA et al., 2015).

Assim, para minimizar as alterações promovidas pela secagem, a obtenção de um modelo matemático é imprescindível para estudar e representar satisfatoriamente os dados experimentais, consequentemente levando a produtos de boa qualidade (MENDONÇA et al., 2015).

O presente trabalho teve como objetivo desenvolver um protótipo de secador solar de baixo custo e de exposição direta utilizando materiais alternativos para a desidratação de goiaba, e avaliar a eficiência do processo, através do ajuste de diferentes modelos para os dados experimentais, e a qualidade físico-química do produto final.

\section{MATERIAL E MÉTODO}

\section{Local de estudo}

O experimento foi desenvolvido no Laboratório de Agroindústria da Universidade Federal do Vale do São Francisco - UNIVASF, campus Ciências Agrárias, Petrolina-PE. O clima local da região

é classificado como BSh (Semiárido), segundo a classificação de Köppen e Geiger,, com precipitação inferior a $500 \mathrm{~mm}$, com chuvas concentradas no verão, com temperaturas variando de 21,9 a $32,5^{\circ} \mathrm{C}$ (KÖPPEN; GEIGER, 1928).

\section{Beneficiamento da matéria-prima}

Foram utilizadas goiabas vermelha cv. 'Paluma', adquiridas junto a agricultores familiares da cidade de Petrolina-PE. Os frutos foram selecionados de acordo com o grau de maturação maduro, 
apresentando $100 \%$ da coloração da casca verde-claro, ausência de injúrias e firmeza, sendo levados sob refrigeração em cooler de plástico para o Laboratório de Agroindústria da Univasf. Em seguida, foram lavados e procedeu-se à sanitização com solução aquosa contendo 50 ppm de cloro ativo durante 15 minutos, e lavados novamente com água corrente para retirada do excesso de cloro.

Os frutos foram descascados de forma manual com o auxílio de facas de aço inox, cortados ao meio, retirado a semente, posteriormente e fatiados em cubos. A secagem ocorreu entre os dias 26 e 27/01/2016, entre 08:30 e 16:30 h. Durante esse período a precipitação pluviométrica foi de 0,0 $\mathrm{mm}$ e a umidade relativa do ar média de $50 \%$. Durante o processo, no período noturno os frutos foram armazenados em dessecadores, e submetidos à radiação solar no dia seguinte até o termino do processo (Figura 1).

Figura 1. Goiaba desidratada com uso de energia solar.

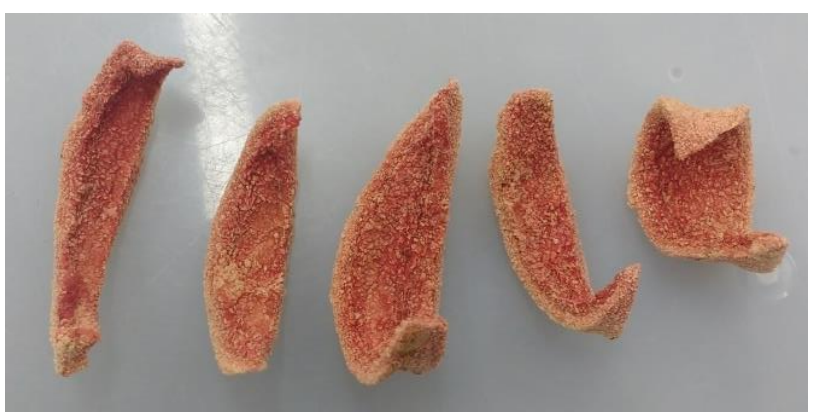

Fonte: Arquivo dos Autores (2020).

\section{Construção do Secador Solar}

Para a construção do secador solar (Figura 2) foi utilizado um tambor de aço com capacidade para $200 \mathrm{~L}$, este foi cortado ao meio em sentido longitudinal obtendo-se 02 secadores. Após o corte, foi afixada uma cantoneira de abas iguais aço para apoiar um vidro de $4 \mathrm{~mm}$ de espessura, com comprimento de 80,5 cm e largura de 69,5 cm. Em uma das laterais foi adaptado uma porta, para permitir a entrada das amostras a serem secas. No interior do secador foram colocadas cantoneiras de metal para apoiar a tela que receberá o material para desidratação. Todo o tambor foi polido com lixa $\mathrm{n}^{\circ} 80$ e pintado de preto fosco visando aumentar a temperatura no interior do mesmo. 
Figura 2. Secador solar baixo custo (A); detalhe com a escotilha de ventilação aberta e grade para suporte (B).

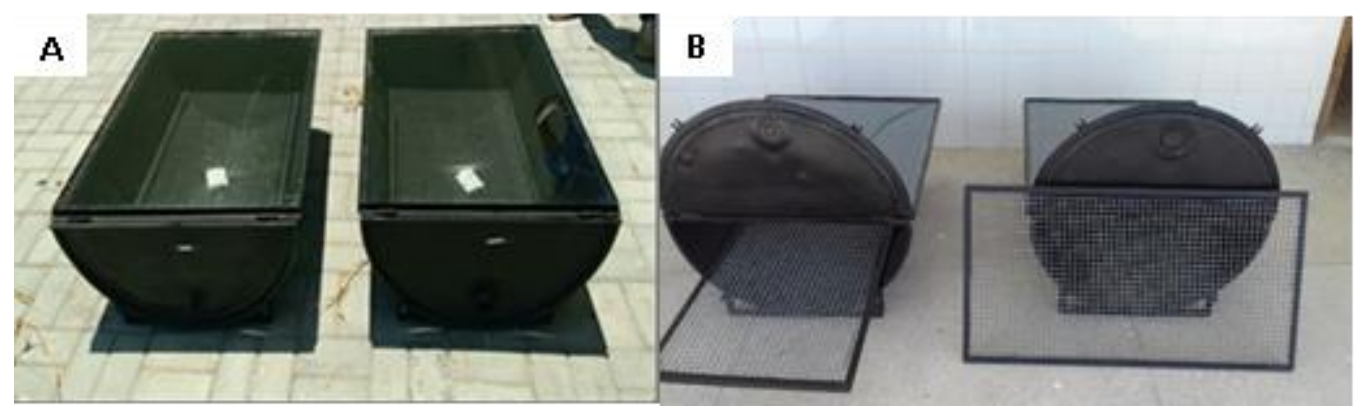

Fonte: Arquivo dos Autores (2020).

A eficiência do processo foi avaliada mediante o monitoramento da à temperatura interna do secador com uso de um termômetro a infravermelho. Além disso, a temperatura do ambiente e a radiação solar foram obtidas a partir de dados fornecidos pelo Instituto Nacional de Meteorologia (INMET), referentes à Estação Automática de Petrolina (Código: OMM 81991).

\section{Cinética de secagem e ajuste de modelos matemáticos}

Para construção da cinética de secagem, a matéria-prima foi avaliada quanto ao teor de umidade por secagem direta em estufa com circulação de ar forçado a $105^{\circ} \mathrm{C}$, até atingir peso constante (IAL, 2008). E para avaliação da taxa de secagem, as fatias foram retiradas do secador solar em intervalos regulares de tempo para determinação da massa das amostras utilizando uma balança semi-analítica com precisão de 0,01 g. Os dados foram utilizados para avaliar a razão de umidade em função do tempo de secagem, que foi finalizada quando houve equilíbrio de umidade em base seca (\% b.s.), e a partir dos dados obtidos, foram expressos na forma de razão de umidade (Eq. 1).

$$
R U=\frac{(U-U e)}{(U i-U e)}
$$

Em que: RU - razão de umidade (adimensional); U - umidade contida no tempo t (\% b.s.); Ue Umidade de equilíbrio (\% b.s.), e Uo - Umidade inicial (\% b.s.). 
Os modelos semi-teóricos de Aproximação, Dois Termos, Exponencial de Dois Termos, Handerson e Pabis, Logarítmico, Midilli, Newton e Page foram utilizados para ajustar às curvas de secagem (Tabela 1).

Aplicou-se ao ajuste dos dados experimentais, os modelos matemáticos apresentados na Tabela 1. Os modelos foram ajustados às curvas da cinética de secagem, e a construção dos gráficos foi feita utilizando o software Sigma Plot 11.0.

Tabela 1. Modelos matemáticos utilizados para predizer o processo de secagem.

\begin{tabular}{ccc}
\hline Modelo Matemático & Equação & Referência \\
\hline Aproximação & $R U=a \cdot \exp (-k \cdot t)+(1-a) \exp (-k \cdot b \cdot t)$ & Santos et al. (2013) \\
Dois termos & $R U=a \cdot \exp \left(-k_{0} \cdot t\right)+b \cdot \exp \left(-k_{1} \cdot t\right)$ & Santos et al. (2013) \\
Exponencial de Dois & $R U=a \cdot \exp (-k \cdot t)+(1-a) \exp (-k \cdot a \cdot t)$ & Radünz et al. (2011) \\
Termos & $R U=a \cdot \exp (-k \cdot t)$ & Radünz et al. (2011) \\
Handerson e Pabis & $R U=a \cdot \exp (-k \cdot t)+c$ & Santos et al. (2014) \\
Logaritmo & $R U=a \cdot \exp \left(-k \cdot t^{n}\right)+b \cdot t$ & Santos et al. (2014) \\
Midilli & $R U=\exp (-k \cdot t)$ & Santos et al. (2014) \\
Newton & $R U=a \cdot \exp \left(-k \cdot t^{n}\right)$ & Alexandre et al. (2013) \\
Page & $R$
\end{tabular}

Em que: RU, razão de umidade, adimensional; $\mathrm{t}$, tempo de secagem, $\mathrm{k}, \mathrm{k}_{0}, \mathrm{k}_{1}$, constantes de secagem específica para $\mathrm{o}$ modelo, $\mathrm{s}^{-1}$; e a, b, c, $\mathrm{n}$ - coeficientes do modelo.

Para avaliar qual modelo produziu os melhores resultados, utilizou-se como parâmetros o coeficiente de determinação $\left(\mathrm{R}^{2}\right)$ e o desvio quadrático médio (Equação 2)

$$
D Q M=\sqrt{\frac{\sum(\text { RUpred }-R U \exp )^{2}}{n}}
$$

Em que: DQM - desvio quadrático médio; RUpred - razão de umidade predito pelo modelo; RUexp - razão de umidade experimental e n - número de observações.

\section{Caracterização físico-química da matéria-prima in natura e desidratada}

Os frutos in natura e desidratado foram avaliados quanto aos parâmetros de: teor de água, determinado por secagem direta em estufa com convecção forçada de ar, em temperatura de $105 \pm 1$ ${ }^{\circ} \mathrm{C}$, até peso constante; $\mathrm{pH}$, através do método potenciométrico, por meio de um medidor de $\mathrm{pH}$ de bancada (pHametro) com precisão de 0,01 ; sólidos solúveis, utilizando-se um refratômetro tipo Abbe, com resultados expressos em ${ }^{\circ}$ Brix; acidez titulável, expressa em teor de ácido cítrico (g. 
$100 \mathrm{~g}^{-1}$ ), foi determinada por volumetria ácido-base empregando a solução de hidróxido de sódio a 0,1 mol.L $\mathrm{L}^{-1}$ e a solução alcóolica de fenolftaleína a $1 \%$ como indicador. Estas análises foram conduzidas conforme as Normas Analíticas do Instituto Adolf Lutz (IAL, 2008). O teor de vitamina C (ácido ascórbico) foi quantificado por volumetria de óxido-redução, através da metodologia descrita por Baccan (2011), empregando a solução padrão de iodo a 0,03 mol.L ${ }^{-1}$ e a solução de amido a $1 \%$ como indicador. Todas as análises foram realizadas em triplicata.

\section{Caracterização da cor da matéria-prima in natura e desidratada}

A cor foi aferida, utilizando-se um colorímetro digital portátil da marca Konica Minolta, modelo CR 10, com sistema de cor Cielab, sendo obtidos os parâmetros $L^{*}$, que indica luminosidade ou brilho e varia do claro (branco; 100) ao escuro (0: escuro/opaco); a*, que indica a cromaticidade no eixo de cor verde (-) para vermelha (+); e b*, que indica a cromaticidade no eixo da cor azul (-) para amarela (+) (LOZANO, 1978). As leituras de cor foram realizadas em quadruplicata.

\section{Análise estatística}

Os graus de normalidade dos dados foram avaliados pelo teste de Shapiro-Wilk, e os dadosexperimentais da avaliação físico-química e da cor foram submetidos a análise de variância em delineamento inteiramente casualizado (DIC), com dois tratamentos e quatro repetições. A comparação das médias dos tratamentos foi feita por teste de hipótese, utilizando o teste t em nível de 5\% $(p<0,05)$ de probabilidade, utilizando o software SigmaPlot versão 11.0.

\section{RESULTADOS E DISCUSSÃO}

\section{Avaliação da eficiência do secador solar}

Analisando a Figura 3, é possível notar que durante o decorrer da secagem o secador solar atingiu uma temperatura média de $49,1^{\circ} \mathrm{C}$, com valores mínimos e máximos de 37 e $57^{\circ} \mathrm{C}$, respectivamente. Para a temperatura do ambiente, obteve-se um valor médio de $29,3^{\circ} \mathrm{C}$, com valores mínimos e máximos de 25 e $34,5^{\circ} \mathrm{C}$, respectivamente. No que se refere à radiação solar, durante o período de secagem, os valores mínimo, máximo e médio foram respectivamente 763, 2793, e 2001 $\mathrm{kJ} . \mathrm{m}^{-2}$ respectivamente. 
Figura 3. Variação da temperatura do ar no interior e exterior do secador solar, e da radiação solar durante a secagem.

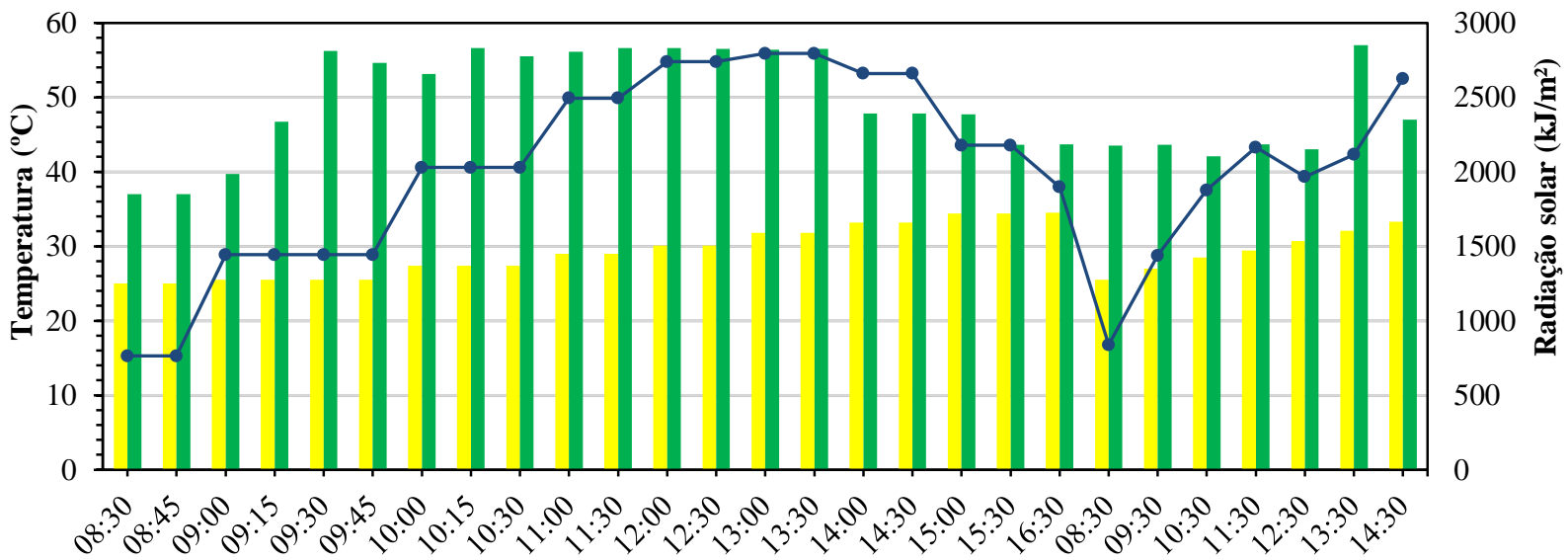

Horário de secagem (horário)

Temperatura Externa $\quad$ Temperatura Interna $\quad \longrightarrow$ Variação da radiação solar durante a secagem

Fonte: Elaborado pelos Autores (2020).

Durante todo o processo de secagem, a temperatura interna foi maior em relação à do ar (ambiente), justificando-se a composição do secador, visto que o tambor metálico é um bom condutor térmico. Além disso, o secador foi pintado de preto por dentro e por fora, e isso resulta em maior absorção da energia solar (GALLE et al., 2016).

O protótipo desenvolvido proporcionou, em condições de clima semiárido, que é caracterizado pela baixa umidade do ar, com temperaturas elevadas, e alta incidência de radiação, solar uma diferença de temperatura média de $19,7^{\circ} \mathrm{C}$, máxima de $30,7^{\circ} \mathrm{C}$ e mínima de $9,2^{\circ} \mathrm{C}$, atestando uma ótima eficiência do sistema.

Nunes et al. (2019), ao desenvolverem um secador solar de exposição indireta com câmara de secagem acoplada, em testes experimentais na secagem de banana prata em Campina Grande - PB, com condições climáticas semiáridas, mensuraram temperaturas próximas, para o ar de secagem no interior da câmara de secagem em torno de $45^{\circ} \mathrm{C} \pm 5^{\circ} \mathrm{C}$, ou seja, temperaturas entre $40^{\circ} \mathrm{C}$ e $50^{\circ} \mathrm{C}$. Ainda de acordo com o autor, essa faixa de temperatura é considerada ideal para a desidratação de frutas e hortaliças. 
Figura 4. Curva de secagem da goiaba vermelha em secador solar de baixo custo e de exposição direta.

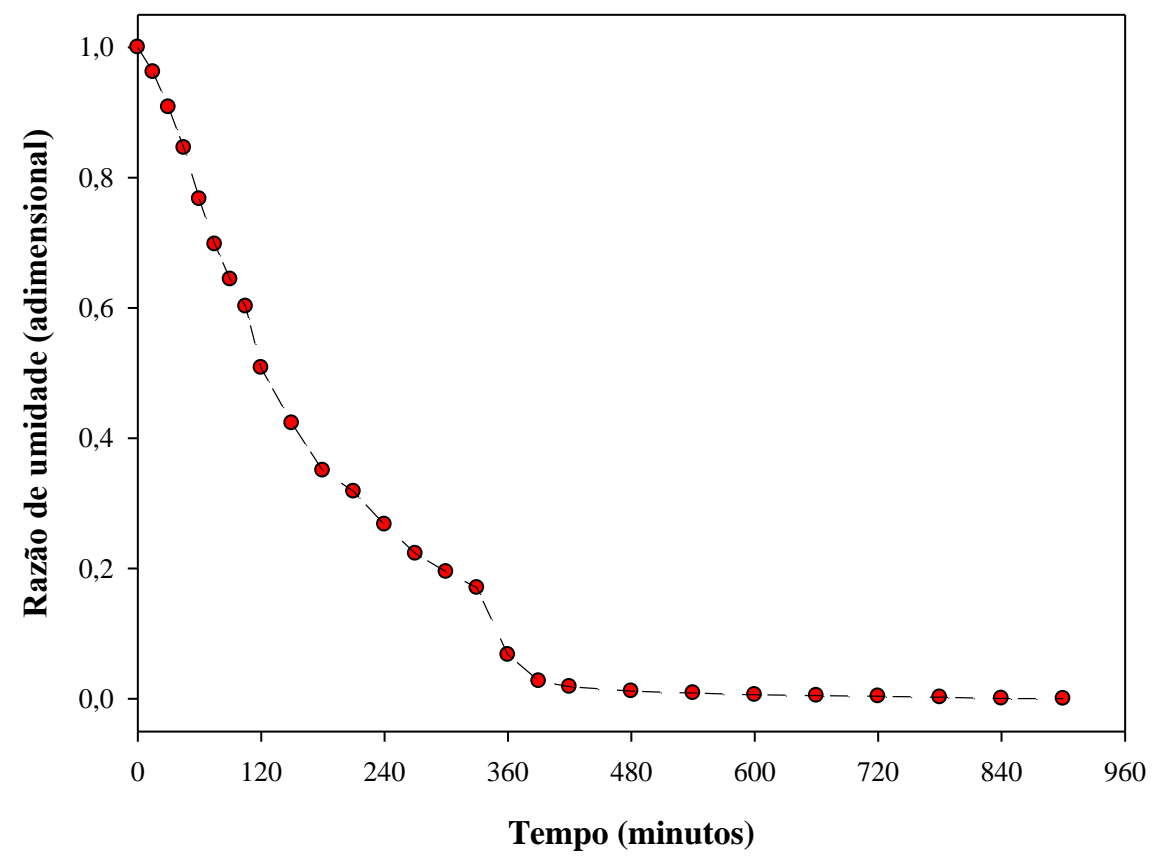

Fonte: Elaborado pelos Autores (2020).

Na Figura 4, tem-se a curva de secagem da goiaba, em função da razão de umidade e o tempo de secagem. As amostras de goiaba submetidas à secagem solar tinham um teor médio de umidade inicial de 596,21\% (u.bs.) e ao final do processo obteve-se umidade final do produto desidratado de 9,82\% (u.bs.), em 15 horas de secagem, sendo que no início da secagem ocorreu diminuição acentuada da umidade, em seguida ocorreu uma redução moderada até se estabilizar.

De acordo com o demonstrado na Tabela 2, pode-se constatar que todos os modelos analisados exceto o de Newton se ajustaram de maneira satisfatória, apresentando coeficientes de determinação superiores ou próximos a 0,99 e o DQM próximos a 0,01, levando-se em consideração que para o ajuste ser considerado satisfatório o R²>0,99 (GONELI et al., 2009). 
Tabela 2. Parâmetros dos modelos ajustados aos dados de secagem dos frutos de goiaba vermelha em secador solar; coeficiente de determinação $\left(R^{2}\right)$ e desvio quadrático médio (DQM).

\begin{tabular}{|c|c|c|c|c|c|c|c|c|c|}
\hline \multirow[t]{2}{*}{ Modelo } & \multicolumn{7}{|c|}{ Parâmetros } & \multirow[t]{2}{*}{$\mathbf{R}^{2}$} & \multirow[t]{2}{*}{ DQM } \\
\hline & $\mathbf{a}$ & $\mathbf{b}$ & $\mathbf{k}$ & $\mathbf{k}_{0}$ & $\mathbf{k}_{1}$ & c & $\mathbf{n}$ & & \\
\hline Aproximação & $-11,8909$ & 0,9488 & 0,0101 & - & - & - & - & 0,9951 & 0,0253 \\
\hline Dois termos & 0,5346 & 0,5346 & - & 0,0061 & 0,0061 & - & - & 0,9912 & 0,0348 \\
\hline $\begin{array}{l}\text { Exponencial } \\
\text { de dois } \\
\text { termos }\end{array}$ & 1,7708 & - & 0,0079 & - & - & - & - & 0,9951 & 0,0250 \\
\hline $\begin{array}{c}\text { Handerson e } \\
\text { Pabis }\end{array}$ & 1,0913 & - & 0,0063 & - & - & - & - & 0,9963 & 0,0164 \\
\hline Logaritmo & 1,0908 & - & 0,0056 & - & - & $-0,0338$ & - & 0,9933 & 0,0297 \\
\hline Midilli & 1,0097 & $-1,1302.10^{-5}$ & 0,0021 & - & - & - & 1,1883 & 0,9956 & 0,0247 \\
\hline Newton & - & - & 0,0056 & - & - & - & - & 0,9863 & 0,0407 \\
\hline Page & 1,0075 & - & 0,0020 & - & - & - & 1,2038 & 0,9954 & 0,0245 \\
\hline
\end{tabular}

Em que: RU, razão de umidade, adimensional; t, tempo de secagem, min; $\mathrm{k}, \mathrm{k}_{0}, \mathrm{k}_{1}$, constantes de secagem específicas para o modelo, $\min ^{-1} ; \mathrm{a}, \mathrm{b}, \mathrm{c}, \mathrm{n}$, coeficientes do modelo.

Fonte: Elaborado pelos Autores (2020).

Entre os modelos estudados o de Handerson e Pabis foi o que melhor se ajustou aos dados obtidos durante o procedimento, uma vez que apresentou coeficiente de determinação superior a 0,996 para todos os ensaios realizados, com desvio quadrático médio menor que 0,02 .

Na Figura 5, tem-se a representação do ajuste dos valores obtidos durante a operação para o modelo matemático de Handerson e Pabis, podendo-se assim constatar o ajuste satisfatório do modelo a cinética de secagem de frutos de goiaba 'Paluma'. 
Figura 5. Cinética de secagem da goiaba vermelha em secador solar de baixo custo e de exposição direta ajustada pelo modelo de Handerson e Pabis.

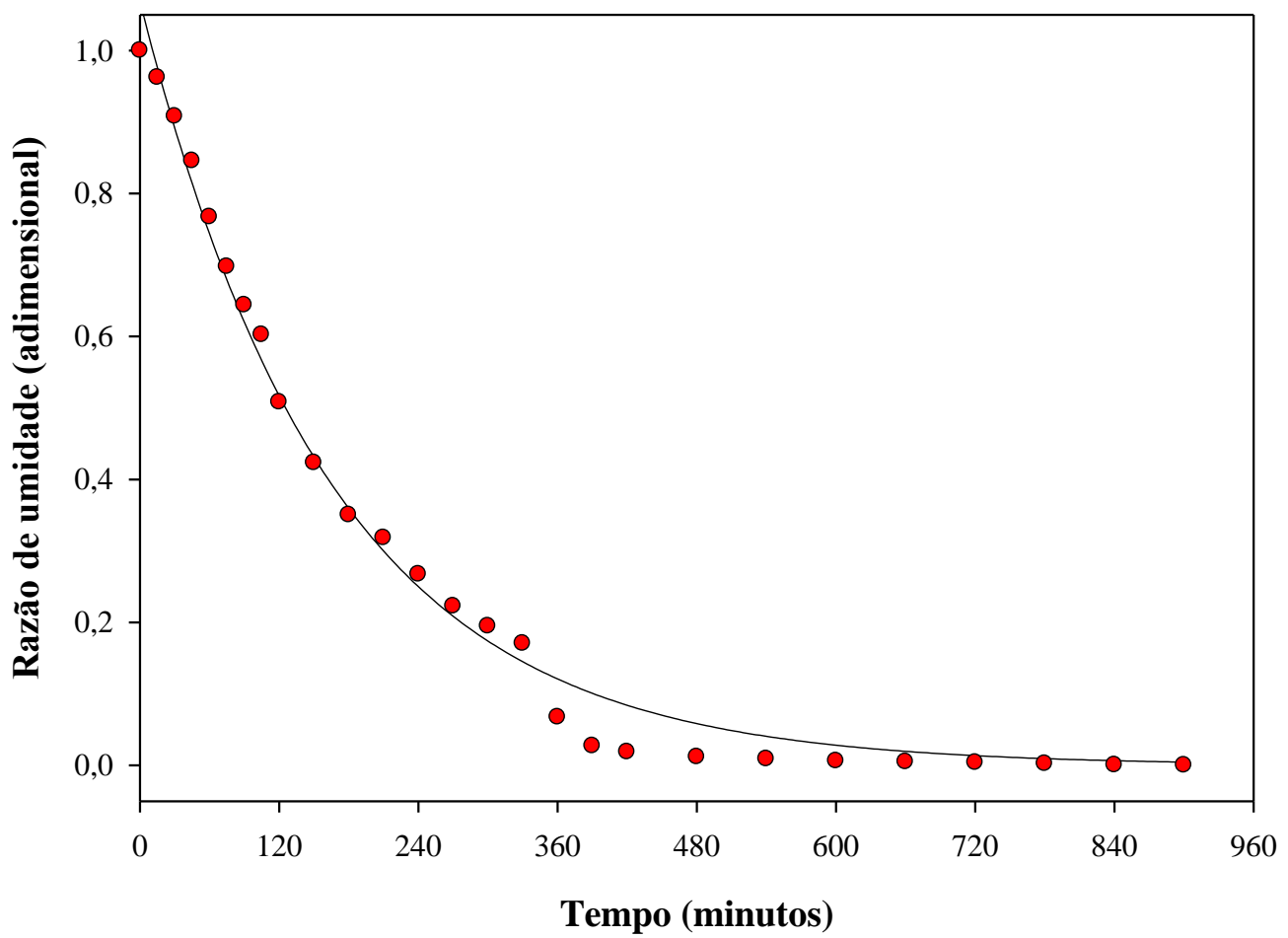

Fonte: Elaborado pelos Autores (2020).

Cabral Filha et al. (2016), ao estudarem a cinética de secagem do resíduo da goiaba em camada fina, constataram que, os dados experimentais se ajustaram de maneira satisfatória aos modelos de Henderson e Pabis e Logarítmico, sendo o modelo de Page o que melhor se adequou para descrever o processo.

\section{Avaliação físico-química do fruto in natura e desidratado sob secagem solar}

Houve uma redução significativa $(p<0,05)$ do $\mathrm{pH}$ da goiaba após a secagem (Tabela 3). O valor, que na amostra antes da secagem era de 3,71 diminuiu para 3,57 no produto seco. Esta queda pode ser atribuída à presença de grupos carboxílicos livres, gerados a partir da desmetoxilação da pectina proveniente da ação da pectina metilesterase presente na parede celular dos vegetais (RAMOS et al., 1998).

Em relação à acidez, observa-se um aumento significativo após a secagem (Tabela 3). A goiaba seca apresentou nível de acidez 5,8 vezes maior do que o fruto in natura. Esse aumento, é 
devido a perda de água do alimento, e como resultado, tem um aumento na concentração de constituintes químicos no produto final, a exemplo do teor de ácido cítrico presente no alimento (TONTUL; TOPUZ, 2017). Além disso, de acordo com Reis et al. (2015), quanto menor o teor de acidez titulável no fruto, maior será seu estado de conservação, o que reflete diretamente na qualidade de um produto final para o consumo.

Tabela 3. Caracterização físico-química da goiaba vermelha in natura e seca com uso de energia solar.

\begin{tabular}{cccc}
\hline Parâmetro & Goiaba in natura & Goiaba seca & P valor \\
\hline $\mathrm{pH}$ & $3,71 \pm 0,01 \mathrm{a}$ & $3,57 \pm 0,01 \mathrm{~b}$ & $<0,001$ \\
Acidez titulável $(\mathrm{g}$ de ácido & $0,68 \pm 0,01 \mathrm{~b}$ & $3,96 \pm 0,05 \mathrm{a}$ & $<0,001$ \\
cítrico. $\left.100 \mathrm{~g}^{-1}\right)$ & & & \\
Sólidos solúveis $\left({ }^{\circ} \mathrm{Brix}\right)$ & $10,34 \pm 0,08 \mathrm{~b}$ & $61,90 \pm 0,42 \mathrm{a}$ & $<0,001$ \\
Teor de água $(\%$ b.u. $)$ & $85,64 \pm 0,21 \mathrm{a}$ & $12,01 \pm 1,70 \mathrm{~b}$ & $<0,001$ \\
Vitamina C $\left({\left.\mathrm{mg} .100 \mathrm{~g}^{-1}\right)}^{6}\right.$ & $66,85 \pm 1,13 \mathrm{~b}$ & $401,40 \pm 11,35 \mathrm{a}$ & $<0,001$
\end{tabular}

Valores médios \pm desvio padrão. As médias seguidas pela mesma letra e na mesma linha não diferem estatisticamente entre si. Foi aplicado o teste $\mathrm{t}$ em nível de $5 \%$ de probabilidade. $\mathrm{P}$ valor - nível descritivo ou probabilidade de significância.

Fonte: Elaborado pelos Autores (2020).

A análise estatística dos dados mostrou que houve diferença significativa $(p<0,05)$ entre o teor de sólidos solúveis da goiaba in natura e seca (Tabela 3). Observou-se um aumento destes sólidos na goiaba seca, que apresentou valor médio de $61,90^{\circ}$ Brix. Esse resultado demonstra que ocorre a concentração do açúcar natural da fruta quando a água é retirada após o processo de secagem (ELIAS et al., 2008).

O teor de água médio obtido para a fruta in natura foi de $85,64 \%$ b.u. e o teor de água final, após a secagem foi de $12 \%$ b.u., valor este, em conformidade com a legislação brasileira por meio da Resolução RDC nº 272 de 22 de setembro de 2005 da Agência Nacional de Vigilância Sanitária, que preconiza um valor máximo $25 \%\left(\mathrm{~g} .100 \mathrm{~g}^{-1}\right)$ de umidade para produtos de frutas secos ou desidratados devem apresentar no (BRASIL, 2005). De acordo com Tontul; Topuz (2017), essa redução da água por meio da secagem, confere maior vida de prateleira ao produto, evitando a degradação, e o desenvolvimento de substancias nocivas para o consumidor.

Após a secagem, verificou-se um aumento de cerca de 500\% na concentração do teor de vitamina C em relação ao teor na goiaba in natura, aumento superior ao relatado por Elias et al. (2008), que

Nucleus, v.17, n.2, out.2020 
constataram um aumento de 300\% na avaliação nutricional de caqui cv. Fuyu submetido à desidratação osmótica e secagem por convecção em relação ao fruto in natura.

\section{Avaliação da cor da polpa do fruto in natura e desidratado sob secagem solar}

No que se diz respeito ao $\mathrm{L}^{*}$ (luminosidade) que varia de 0 (preto) a 100 (branco), houve redução significativa deste parâmetro após a secagem, caracterizando um escurecimento das amostras. Quanto a intensidade de vermelho (a+) ou verde (a-), de acordo com Cardoso et al. (2007), os valores menores (a-) correspondem ao padrão de cor mais fraco (aspecto fosco do objeto) e valores mais altos $(\mathrm{a}+)$ ao padrão de cor mais intensa, aspecto desejado para os alimentos, sendo assim a goiaba in natura continua sendo mais atrativa para o consumidor, por apresentar espectro positivo indicando cores mais fortes em relação a goiaba seca.

Tabela 4. Coloração da goiaba in natura e seca com uso de energia solar.

\begin{tabular}{cccc}
\hline Parâmetro & Goiaba in natura & Goiaba seca & P valor \\
\hline $\mathrm{L}^{*}$ & $42,77 \pm 1,47 \mathrm{a}$ & $35,02 \pm 1,05 \mathrm{~b}$ & 0,004 \\
$\mathrm{a}^{*}$ & $27,10 \pm 1,15 \mathrm{a}$ & $21,35 \pm 1,22 \mathrm{~b}$ & 0,008 \\
$\mathrm{~b}^{*}$ & $17,57 \pm 0,93 \mathrm{~b}$ & $23,57 \pm 0,07 \mathrm{a}$ & $<0,001$
\end{tabular}

As médias seguidas pela mesma letra e na mesma linha não diferem estatisticamente entre si. Foi aplicado o teste t em nível de 5\% de probabilidade. P valor - nível descritivo ou probabilidade de significância.

Referente à intensidade de amarelo (+b) houve diferença significativa entre as amostras, e a goiaba seca conferiu uma maior coloração amarelada, correspondendo as modificações químicas sofridas pelos carotenoides, pigmentos responsáveis pela coloração vermelho-amarelada, devido a exposição em elevadas temperaturas (MACHADO et al., 2019). O comportamento apresentado era esperado, visto que, a secagem interfere nos processos metabólicos relacionados aos frutos climatéricos, que são acelerados e, consequentemente, a interferência na cor (MENDES et al., 2013).

\section{CONCLUSÃO}

O processo de secagem, a partir da utilização da energia solar, possibilitou a secagem dos frutos de goiaba dentro de um período de 15 horas, por meio do desenvolvimento de um protótipo simples, com incremento médio de temperatura de $19,7^{\circ} \mathrm{C}$, apresentando boa eficiência.

O modelo de Handerson e Pabis foi o que melhor se ajustou aos dados obtidos para predição do processo. 
A secagem solar levou a uma redução significativa do pH e do teor de água, além de atender a legislação brasileira vigente quanto ao teor de umidade.

Após a secagem, verificou-se um aumento da acidez, e de cerca de $500 \%$ na concentração do teor de vitamina $\mathrm{C}$ em relação ao teor na goiaba in natura.

\section{AGRADECIMENTOS}

Ao Programa Institucional de Bolsas de Extensão da Universidade Federal do Vale do São Francisco pela concessão da bolsa para realização das atividades de pesquisa e extensão (Edital $\mathrm{n}^{\circ}$ 01/2016 - Proex/Univasf).

\section{REFERENCIAS}

ALEXANDRE, H. V.; SILVA, F. L. H.; GOMES, J. P.; SILVA, O. S.; CARVALHO, J. P. D.; LIMA, E. E. Cinética de secagem do resíduo de abacaxi enriquecido. Revista Brasileira de Engenharia Agrícola e Ambiental, v.17, n.6, p. 640-646, 2013.

BACCAN, N. Química analítica quantitativa elementar. Edgar Blucher: São Paulo, Brasil. 308p. 2011.

BRASIL. Agência Nacional de Vigilância Sanitária. Resolução da Diretoria Colegiada - RDC n. 272, de 22 de setembro de 2005. Dispõe sobre o "Regulamento Técnico para produtos de vegetais, produtos de frutas e cogumelos comestíveis", Diário Oficial da União, Brasília, DF, 2005.

CABRAL FILHA, M. C. S.; ARAUJO, S. C.; SILVA, G. M. S.; CANUTO, M. F. C. S.; MARTINS, G. M. V. Cinética de secagem do resíduo da goiaba (Psidium guajava L.) em camada fina. Revista Verde de Agroecologia e Desenvolvimento Sustentável, v.11, n.4, p. 99-104, 2016.

CARDOSO, W. S.; PINHEIRO, F. A.; PATELLI, T.; PEREZ, R.; RAMOS, A. M. Determinação da concentração de sulfito para a manutenção da qualidade da cor em maçã desidratada. Revista Analytica, v.29, p.66-72, 2007.

ELIAS, N. de F.; BERBERT, P. A.; MOLINA, M. A. B. de.; VIANA, A. P.; DIONELLO, R. G.; QUEIROZ, V. A. V. Avaliação nutricional e sensorial de caqui cv Fuyu submetido à desidratação osmótica e secagem por convecção. Ciência e Tecnologia de Alimentos (Impresso), v. 28, n. 2, p. 322-328, 2008.

FARIA, R. Q.; TEIXEIRA, I. R.; DEVILLA, I. A.; ASCHERI, D. P.; RESENDE, O. Cinética de secagem de sementes de crambe. Revista Brasileira de Engenharia Agrícola e Ambiental, v.16, n. 5, p. 573-584, 2012.

GAlle, N. B. C.; ALVES, N. M. C.; CASTRO, R. L. O.; VILELA, A. O.; SILVA, M. I. P. Secador solar para secagem de frutas reutilizando materiais descartados da construção civil. A Barriguda: Revista Científica, v.6, p. 593-602, 2016.

Nucleus, v.17, n.2, out.2020 
GILL, K. S.; DHALIWAL, H. S.; MAHAJAN, B. V. C.; PALIYATH, G.; BOORA, R. S. Enhancing postharvest shelf life and quality of guava (Psidium guajava L.) cv. Allahabad Safeda by pre-harvest application of hexanal containing aqueous formulation. Postharvest Biology and Technology, v.112, p.224-232, 2016.

GONELI, A. L. D.; CORRÊA, P. C.; AFONSO JÚNÍOR, P. C.; OLIVEIRA, G. H. H. Cinética de secagem dos grãos de café descascados em camada delgada. Revista Brasileira de Armazenamento, Especial Café, v.11, p. 64-73, 2009.

IAL - Instituto Adolfo Lutz. Métodos físico-químicos para análise de alimentos. 4. ed. São Paulo: Instituto Adolfo Lutz, 2008. 1020 p.

IBGE. Banco de dados agregados do Instituto Brasileiro de Geografia e Estatística. 2014.

Disponível em: http://www.sidra.ibge.gov.br. Acesso em: 13 Abr. 2016.

KÖPPEN, W.; GEIGER, R. Klimate der Erde. Gotha: Verlag Justus Perthes. 1928. Wall-map $150 \mathrm{~cm} x 200 \mathrm{~cm}$.

LOZANO, R. D. “El color y su medición”, Ed. I Américalee S.R.L, Buenos Aires, 1978, 640 p.

MACHADO T. F.; MONTEIRO E. R.; TIECHER A. Estabilidade química, físico-química e antioxidante de polpa de Physalis pasteurizada e não pasteurizada sob congelamento. Brazilian Journal of Food and Technology, v.22, p.e2017149, 2019.

MENDES, G. R., FREITAS, C. H., SCAGLIONI, P. T., SCHMIDT, C. G., FURLONG, E. B. Condições para desidratação osmótica de laranjas e as propriedades funcionais do produto. Revista Brasileira de Engenharia Agrícola e Ambiental, v.17, n.11, p.1210-1216, 2013.

MENDONÇA, A. P.; SAMPAIO, P. DE T. B.; ALMEIDA, F. DE A. C.; FERREIRA, R. F.; NOVAIS, J. M. Determinação das curvas de secagem das sementes de andiroba em secador solar. Revista Brasileira de Engenharia Agrícola e Ambiental, v.19, n.4, p.382-387, 2015.

MOREIRA, I. S.; SILVA, W. P.; CASTRO, D. S.; SILVA, L. M. M.; GOMES, J. P. G.; SILVA, C. M. D. P. S. Production of kiwi snack slice with different thickness: Drying kinetics, sensory and physicochemical analysis. Australian Journal of Crop Science, v.12, n.5, p. 778-787, 2018.

NUNES, A.G.; SALES, A. Q.; MARTINS, R. C. G.; GRILO, M. B. Secador solar usado na secagem de banana. Brazilian Journals of Business, v.1, n.4, p. 1850-1857, 2019.

PRAKASH, O.; ANILKUMAR, A. Solar greenhouse drying: A review. Renewable and Sustainable Energy Reviews, v.29, n.C, p. 905-910, 2013.

QUINTERO-RAMOS, A.; DE LA VEGA, C.; HERNÁNDEZ, E.; ANZALDÚA-MORALES, A. Effect of conditions of osmotic treatment on the quality of dried apple dices, In: BARBOSA CÁNOVAS, G. V.; OKOS, M. R. (Ed.) Food dehydration, Aiche Symposium Series: New York, NY, US, v.89, n.297, p. 108-113, 1993.

RADÜNZ, L. L.; AMARAL, A. S.; MOSSI, A. J.; MELO, E. C.; ROCHA, R. P. Avaliação da cinética de secagem de carqueja. Engineering in Agriculture, v.19, n.1, p. 19-27, 2011. 
REIS, D. R.; SANTOS, P.; SILVA, F. S.; PORTO, A. G. Influência das características do ar na cinética de secagem de pimenta variedade bico. Brazilian Journal Food Technology, v.18, n.2, p.146-154, 2015.

RODRIGUES, M.S.; SANTANA, M.C.; UCHOA, A. L. P.; MENEZES, A. X. S. M.; CAVALCANTE, Í. H. L.; LIMA, A. M. N. Delineation of management zones based on soil physical attributes in an irrigated guava field in the Semi-Arid region, Brazil. African Journal of Agricultural Research, v.10, n.45, p.4185-4192, 2015.

SAHOO, N. R.; PANDA, M. K.; BAL, L. M.; PAL, U. S.; SAHOO, D. Comparative study of MAP and shrink wrap packaging techniques for shelf life extension of fresh guava. Scientia Horticulturae, v.182, n.23, p.1-7, 2015.

SANTANA, E. A.; LOBO, J. T.; PEREIRA, R. N.; LIMA, A. M. N.; CUNHA, J. C.; CAVALCANTE, I. H. L. Micronutrientes foliares na goiabeira fertirrigada com biofertilizante e nitrogênio no semiárido, Comunicata Scientiae, v.7, n.4, p.523-527, 2016.

SANTOS, D. C.; QUEIROZ, A. J. M.; FIGUEIREDO, R. M. F.; OLIVEIRA, E. N. A. Cinética de secagem de farinha de grãos residuais de urucum. Revista Brasileira de Engenharia Agrícola e Ambiental, v.17, n.2, p.223-231, 2013.

SANTOS, M. N. S.; OLIVEIRA, D. E. C.; RUFFATO, S.; PERREIRA, V. S. Cinética de secagem de grãos de milho da cultivar Pioneer P3646 - 10.14688/1984-3801/GST.V7N2P119-129. Global Science and Technology, v.7, n.2, p.119-129, 2014.

SATER, O.; SOUZA, N. D.; OLIVEIRA, E. A. G., ELIAS, T. F.; TAVARES. R. Estudo comparativo da carbonização de resíduos agrícolas e florestais visando à substituição da lenha no processo de secagem de grãos de café. Revista Ceres, v.58, n.6, p. 717-722, 2011.

SILVA, W. P.; SILVA, C. M. D. P. S.; Gama, F. J. A.; GOMES, J. P. G. de. Mathematical models to describe thin-layer drying and to determine drying rate of whole bananas. Journal of the Saudi Society of Agricultural Sciences, v.13, n.1, p.67-74, 2013.

SOUSA, F. C.; MARTINS, J. J. A.; ROCHA, A. P. T.; GOMES, J. P.; PESSOA, T.; MARTINS, J. N. Predição de modelos sobre a cinética de secagem de folhas de Ziziphus joazeiro Mart. Revista Brasileira de Plantas Medicinais (Impresso), v.17, n.2, p.195-200, 2015.

TONTUL, I.; TOPUZ, A. Spray-drying of fruit and vegetable juices: Effect of drying conditions on the product yield and physical properties. Trends in Food Science \& Technology, v. 63, p. 91-102, 2017.

VASCONCELOS, J. L. L. A.; ANDRADE, S. A. C.; MACIEL, M. I. S.; GUERRA, N. B.; VASCONCELOS, M. A. S. Osmotic dehydration of the Indian fig (Opuntia ficus indica) with binary and ternary solutions. International Journal of Food Science \& Technology, v. 47, n. 11, p. 23592365, 2012.

VISHWASRAO, C.; ANANTHANARAYAN, L. Postharvest shelf-life extension of pink guavas (Psidium guajava L.) using HPMC-based edible surface coatings, Journal of Food Science and Technology, v. 53, p.1966-1974, 2016.

Nucleus, v.17, n.2, out.2020 